Journal for ImmunoTherapy of Cancer

\title{
A heat-shocked melanoma cell lysate vaccine enhances tumor infiltration by prototypic effector $T$ cells inhibiting tumor growth
}

\author{
María Alejandra Gleisner, ${ }^{1,2}$ Cristián Pereda, ${ }^{1,2}$ Andrés Tittarelli (D) ,2,3 \\ Mariela Navarrete, ${ }^{1,2}$ Camila Fuentes, ${ }^{1,2}$ Ignacio Ávalos, ${ }^{1,2}$ Fabian Tempio, ${ }^{1,2}$ \\ Juan Pablo Araya, ${ }^{1,2}$ María Inés Becker, ${ }^{4,5}$ Fermín Eduardo González, ${ }^{2,6}$ \\ Mercedes Natalia López, ${ }^{1,2}$ Flavio Salazar-Onfray ${ }^{1,2}$
}

To cite: Gleisner MA, Pereda C, Tittarelli A, et al. A heatshocked melanoma cell lysate vaccine enhances tumor infiltration by prototypic effector T cells inhibiting tumor growth. Journal for ImmunoTherapy of Cancer 2020;8:e000999. doi:10.1136/jitc-2020-000999

- Additional material is published online only. To view please visit the journal online (http://dx.doi.org/10.1136/jitc2020-000999).

MAG and CP contributed equally.

Accepted 22 June 2020

\section{Check for updates}

(C) Author(s) (or their employer(s)) 2020. Re-use permitted under CC BY. Published by BMJ.

For numbered affiliations see end of article.

\section{Correspondence to} Dr Flavio Salazar-Onfray, Disciplinary Program of Immunology, Institute of Biomedical Sciences, Faculty of Medicine, Universidad de Chile, Santiago, Chile;

fsalazar@u.uchile.cl

Dr Mercedes Natalia López, Disciplinary Program of Immunology, Institute of Biomedical Sciences, Faculty of Medicine, Universidad de Chile, Santiago, Chile;

melopez@uchile.cl

\section{ABSTRACT}

Background Immune checkpoint blocker (ICB) therapy has shown survival benefits for some patients with cancer. Nevertheless, many individuals remain refractory or acquire resistance to treatment, motivating the exploration of complementary immunotherapies. Accordingly, cancer vaccines offer an attractive alternative. Optimal delivery of multiple tumor-associated antigens combined with potent adjuvants seems to be crucial for vaccine effectiveness. Methods Here, a prototype for a generic melanoma vaccine, named TRIMELVax, was tested using B16F10 mouse melanoma model. This vaccine is made of heat shock-treated tumor cell lysates combined with the Concholepas concholepas hemocyanin as adjuvant. Results While B16F10 lysate provides appropriate melanoma-associated antigens, both a generic human melanoma cell lysate and hemocyanin adjuvant contributes with danger signals promoting conventional dendritic type 1 cells (cDC1), activation, phagocytosis and effective antigen cross-presentation. TRIMELVax inhibited tumor growth and increased mice survival, inducing cellular and humoral immune responses. Furthermore, this vaccine generated an increased frequency of intratumor cDC1s but not conventional type 2 dendritic cells (cDC2s). Augmented infiltration of $\mathrm{CD}^{+}, \mathrm{CD}^{+}$and $\mathrm{CD}^{+} \mathrm{T}$ cells was also observed, compared with anti-programmed cell death protein 1 (PD-1) monotherapy, while TRIMELVax/anti-PD-1 combination generated higher tumor infiltration of $\mathrm{CD}^{+}$ T cells. Moreover, TRIMELVax promoted an augmented proportion of $\mathrm{PD}-1^{10} \mathrm{CD}^{+} \mathrm{T}$ cells in tumors, a phenotype associated with prototypic effector cells required for tumor growth control, preventing dysfunctional T-cell accumulation.

Conclusions The therapeutic vaccine TRIMELVax efficiently controls the weakly immunogenic and aggressive B16F10 melanoma tumor growth, prolonging tumor-bearing mice survival even in the absence of ICB. The strong immunogenicity shown by TRIMELVax encourages clinical studies in patients with melanoma.

\section{BACKGROUND}

Immunotherapies based on immune checkpoint blockers (ICBs), targeting inhibitory immune pathways such as cytotoxic $\mathrm{T}$ lymphocyte-associated protein 4 or programmed cell death protein 1 (PD-1), have shown significant success in promoting tumor regression and prolonging survival in patients with cancer, particularly in melanoma and other solid tumors. ${ }^{2}$ However, many patients do not respond or develop resistance to these interventions, bringing the scientific communities to focus their efforts in combinatorial therapies. ${ }^{3}$ A major factor involved in initial resistance to ICB is lack or weak T-cell tumor infiltration, characterizing the so-called "cold tumors." In fact, high lymphocyte infiltration and interferon- $\gamma$ status related to a T-cell inflamed phenotype (hot tumors) constitute key factors for effective anti-PD-1/PD-L1 (programmed cell death ligand 1) therapies. ${ }^{45}$ For this reason, immunological treatments that induce adaptive cellular responses in cold tumor patients may be a desirable goal. In this context, active immunotherapies become once again an attractive alternative and/or complement for cancer treatment. ${ }^{6}$

Different strategies for cancer vaccines have been proposed in the past, including those based on recombinant antigenic polypeptides or proteins, modified whole-tumor cells, dendritic cells (DCs) loaded with tumorassociated antigens (TAAs) or DNA vaccines, with dissimilar effects. ${ }^{6}$ Interestingly, some DC vaccines have demonstrated promising results, such as the Food and Drug Administrationapproved personalized immunotherapy against advanced prostate cancer Sipuleucel-T (Provenge). ${ }^{7}$ Meanwhile, our group has conducted a series of clinical trials using a DC-based vaccine named tumor antigenpresenting cells (TAPCells), ${ }^{8}$ consisting in 
monocyte-derived antigen-presenting cells (APCs) loaded with an allogeneic heat shock (HS)-conditioned melanoma cell lysate named TRIMEL. These clinical studies showed that $\sim 60 \%$ of vaccinated patients developed a delayed-type hypersensitivity (DTH) response against TRIMEL antigens, correlating with a threefold improved overall survival (median: 33 months) compared with DTH-negative patients (median: 11 months).$^{89}$ TRIMEL was generated from a mixture of three human melanoma cell lines expressing several known melanoma-associated antigens (MAAs) such as MART-1/MelanA, gp100, tyrosinase, NY-ESO-1, MAGE, GAGE, MC1R, among others. ${ }^{9}$ Interestingly, HS treatments of tumor cells previous to lysis cause plasma membrane translocation of calreticulin and the release of high-mobility group box-1 (HMGB1) and ATP, acting as danger-associated molecular patterns (DAMPs) that induce optimal DC maturation and tumor antigen cross-presentation. ${ }^{9} 10$

Despite encouraging clinical outcomes, biological diversity among patient cells used for DC vaccines ${ }^{11}{ }^{12}$ and technological challenges related to personalized medicine ${ }^{13}$ have hindered the massive translation of TAPCell therapy into the clinic. For that reason, we propose to bypass these limitations by using a generic therapeutic melanoma vaccine prototype, based on the immunogenic TRIMEL lysate combined with an appropriate adjuvant, which do not require individual adapted manufacturing.

At this respect, previous experimental models using B16F10 melanoma whole cells or derived cell lysates as vaccines generated protective antitumor immune responses only when melanoma cells were genetically modified for expressing strong antigens (ie, ovalbumin), releasing different cytokines (ie, granulocyte-macrophage colony-stimulating factor (GM-CSF)) and/or when combined with ICB. ${ }^{14-16}$ An outstanding example is the GM-CSF gene-transduced tumor vaccine referred to as GVAX, which demonstrated antitumor activity in preclinical cancer models, including the low antigenic B16 melanoma. ${ }^{17}$ However, GVAX and other whole-tumor cell cancer vaccines have shown low objective response rates and very limited improvements of patient survival, suggesting suboptimal immunogenic potential of these approaches, particularly in melanoma. ${ }^{17-19}$ This apparently weak immunogenicity can be due to several reasons, including the absence of appropriate immunological danger signals during immunizations, the suboptimal activation of DCs and/or an inefficient delivery of relevant TAA to resident DC populations responsible for ideal cross-priming of protective $\mathrm{CD} 8^{+} \mathrm{T}$ cells. ${ }^{20-22}$

In this report, we tested a vaccine named TRIMELVax consisting in HS-conditioned TRIMEL plus B16F10 cell lysates combined with Concholepas concholepas hemocyanin $(\mathrm{CCH})$ as an adjuvant. The earliest discovered hemocyanin commonly known as keyhole limpet hemocyanin (KLH) is purified from the giant keyhole limpet gastropod Megathura crenulata and has been successfully used as an adjuvant in many clinical protocols. ${ }^{23}$ Meanwhile, $\mathrm{CCH}$ is a high molecular weight glycoprotein related to oxygen transport in mollusks. It has been described that the highly complex CCH molecule shows a structural stability that contribute to their potent immunostimulatory effects, ${ }^{24}$ strengthening innate and adaptive immunity in mammals and making it useful in cancer immunotherapy. ${ }^{25} 26$ Although both hemocyanins show comparable immunogenic characteristics, ${ }^{27} \mathrm{CCH}$ is made up of intermixed subunits organized as heterododecamers that do not require divalent ions, given greater comparative stability. Unlikely, KLH is formed by homododecamers, whose stability depends on $\mathrm{Ca}^{+2}$ and $\mathrm{Mg}^{+2}$ for maintenance. ${ }^{25}$

Our results showed that TRIMELVax immunizations activate effective cell-mediated and humoral immune responses against B16F10 tumors, inhibiting tumor growth and prolonging mice survival, even in the absence of combined therapy with anti-PD-1 antibodies.

\section{METHODS \\ Mice}

Wild-type C57BL6, pMEL-1 (JAX stock no: 005023) and Nonobese diabetic/severe combined immunodeficiency (NOD-SCID) (JAX stock no: 005557) mice were maintained at animal facility of the Universidad de Chile, Faculty of Medicine. pMEL-1 mice have C57BL6 background and NOD-SCID mice were on NOD/ShiLtSz background. For all experiments, mice between 6 and 12 weeks of age were bred in specific pathogen-free conditions.

\section{Cell culture media and reagents}

Tumor cell lines were maintained in RPMI-1640 (Corning) supplemented with $1 \%$ penicillin/streptomycin (Corning) and 10\% heat-inactivated fetal bovine serum (FBS) (Corning). Bone marrow-derived DC (BMDC) were cultured in RPMI-1640-GlutaMAX (Gibco) supplemented with $1 \%$ penicillin/streptomycin, $55 \mu \mathrm{M}$ 2-mercaptoethanol (Gibco) and 10\% FBS. Fluorescenceactivated cell sorting (FACS) buffer was phosphatebuffered saline (PBS) (Corning), supplemented with 2\% FBS and $2 \mathrm{mM}$ EDTA (Ambion). CCH Inmunocyanin was provided by Biosonda. The gp100 ${ }_{25-33}$ peptide (KVPRNQDWL) was purchased from Genetel Laboratories. Dr Fabiola Osorio (Universidad de Chile) kindly provided FMS-like tyrosine kinasa 3-ligand (FLT3-L). Lipopolysaccharide (LPS), phorbol myristate acetate and ionomycin were purchased from Sigma-Aldrich. Brefeldin-A was from eBioscience.

\section{Cell lines and cell lysates}

Mel1, Mel2 and Mel3 are human melanoma cell lines isolated from metastatic lymph nodes (LNs) of three patients. ${ }^{9}$ B16F10 (ATCCCRL-6475) and MC38 (ATCCCRL-2639) cells were kindly provided by Dr Álvaro Lladser (Fundación Ciencia \& Vida, Chile). FLT3L-expressing B16F10 cells (B16-FLT3L) were kindly provided by Dr María Rosa Bono (Universidad de Chile). 
Cell lysates were made as previously described. ${ }^{9}$ TRIMEL is derived from a mix of equal amounts of Mel1, Mel2 and Mel3 cells, which were taken to a final concentration of $8 \times 10^{6}$ cells $/ \mathrm{mL}$, HS treated at $42^{\circ} \mathrm{C}$ for 1 hour plus 2 hours at $37^{\circ} \mathrm{C}$ and then lyzed through three cycles of freeze/thaw in liquid nitrogen. The HS-conditioned lysate from B16F10 and MC38 cells were prepared using same approach $\left(8 \times 10^{6}\right.$ cells $\left./ \mathrm{mL}\right)$. Tumor cells not HS treated were incubated for 3 hours at $37^{\circ} \mathrm{C}$ before being lyzed.

\section{Tumor challenge and vaccinations}

For therapeutic assays, C57BL6 mice were subcutaneously inoculated with $2.5 \times 10^{4}$ B16F10 or $1 \times 10^{5}$ MC38 cells in lower right flanks. Mice were then immunized subcutaneously on lower left flanks on days 1, 6 and 12 post-tumor challenge with corresponding treatments: (1) lysates of B16F10 cells with or without CCH $(25 \mu \mathrm{g} / \mu \mathrm{L}$, total $200 \mu \mathrm{g} \mathrm{CCH} /$ doses), (2) lysates of HS-conditioned B16F10 cells $\pm \mathrm{CCH}$, (3) 1:1 mixture of B16F10 cell lysate (preconditioned or not with HS) with TRIMEL $\pm \mathrm{CCH}$, (4) 1:1 mixture of HS-conditioned MC38 cell lysate with TRIMEL $\pm \mathrm{CCH}$, (5) CCH or (6) PBS. Each tumor cell lysate doses contained approximately $1.4 \times 10^{6}$ cells in $172 \mu \mathrm{L}$. The mixture of HS-conditioned B16F10 cell lysate plus TRIMEL and CCH corresponds to TRIMELVax. For combination therapy assays, $200 \mu \mathrm{g} /$ dose of anti-PD-1 (CD279) monoclonal antibody (RMP1-14 (BioXCell)) was intraperitoneally administered on days 4, 7 and 11 post-tumor challenges. For survival assays, mice were sacrificed when tumor growth exceeded $1500 \mathrm{~mm}^{3}$. On day 14 after challenge, mice were sacrificed, and tumors, tumor draining LNs (TdLNs) and serum were analyzed.

For prophylactic assays, C57BL6 or NOD-SCID mice were vaccinated subcutaneously at lower left flanks with TRIMELVax or PBS on days $-19,-9$ and -2 before tumor challenge. On day $0,1.5 \times 10^{5} \mathrm{~B} 16 \mathrm{~F} 10$ cells were subcutaneously inoculated at right flanks and tumor growth was measured every 2-3 days.

\section{Flow cytometry and cell sorting}

Antibodies for flow cytometry (BD Pharmigen, eBioscience, BioLegend or Miltenyi Biotec), and viability dye LIVE/DEAD (Thermo Fisher Scientific) were used for cell phenotyping. Depending on the experiment, cells were stained with following antibodies in presence of CD16/31 (Fc-Block): CD11b (M170), I-A/I-E (M5/114.15.2), XCR1 (ZET), CD8a (53.6.7), CD3 (17A2), B220 (RA3-6B2), CD103 (2E7), CD11c (N418), CD69 (IM7), CD24 (M1/49), CD172a (P84), CD45.1 (A20), NK1.1 (PK136), CD4 (GK1.5), CD64 (X54-5/7.1), F4/80 (BM8), CD86 (GL-1), CD24 (M1/69), CD44 (IM7) and PD-1 (29F.1A12). Acquisition and analysis of cell suspensions were performed on FACSVerse and LSR Fortessa X-20 (BD Biosciences) and subsequent analysis was made with FlowJo10 software (FlowJo). Cell sorting was performed on FACS Aria III (BD Biosciences).

\section{In vitro differentiation of BM-DCs}

BM-DCs differentiated in vitro using FLT3-L (FL-DCs) from BM precursor cells of C57BL6 mice femurs and tibias were cultured in BM-DC culture media in presence of $150 \mathrm{ng} / \mathrm{mL}$ of human recombinant FLT3-L (PeproTech) for 7-8 days before use.

\section{Phagocytosis assay}

Prior to HS treatment and lysis, mixtures of Mel1/Mel2/ Mel3 and/or B16F10 cells were stained with $2 \mu \mathrm{M}$ PKH26 (Sigma-Aldrich) following manufacturer's instructions. HS-conditioned PKH26-prelabeled melanoma cell lysates were generated as previously described. $1 \times 10^{5}$ FL-DCs were cocultured with the stained melanoma cell lysates in 1:1 tumor cell:DC ratio for 0 or 3 hours at $37^{\circ} \mathrm{C}$ or $4^{\circ} \mathrm{C}$. After coculture, lysate capture was determined gating in each FL-DC population using flow cytometry. The phagocytic indexes were calculated as: (\% phagocytosis at $37^{\circ} \mathrm{C} / \%$ phagocytosis at $\left.4^{\circ} \mathrm{C}\right) \times 100$.

\section{Activation of FL-DC in vitro}

$1 \times 10^{5}$ FL-DCs were stimulated in 1:1 ratio (taking into account the pre-lysis melanoma cell numbers) with TRIMELVax, TRIMEL, HS-conditioned lysates from B16F10 cells, TRIMEL plus HS-conditioned lysate of B16F10 cells, CCH $(200 \mu \mathrm{g})$, LPS $(100 \mathrm{ng} / \mathrm{mL})$ or kept unstimulated for 24 hours. CD86 expression level was analyzed by flow cytometry.

\section{In vitro and ex vivo antigen cross-presentation assays}

For proliferation assays, $\mathrm{CD} 8^{+} \mathrm{T}$ cells were isolated from pMEL-1 splenocytes by negative selection, using a lineage depletion cocktail of biotinylated antibodies and antibiotin microbeads (Miltenyi Biotec) and labeled with $5 \mu \mathrm{M}$ CellTrace Violet (CTV) (Thermo Fisher Scientific). For in vitro assays, FL-DCs were treated 1:1 with TRIMEL plus HS-conditioned B16F10 cell lysate and CCH $(200 \mu \mathrm{g})$ for 5 hours at $37^{\circ} \mathrm{C}$. For ex vivo assays, inguinal, axillary and brachial LNs were collected from B16-FLT3L tumorbearing mice. Plasmacytoid DC ( $\mathrm{pDC})$, conventional type 1 DC (cDC1) and conventional type 2 DC (cDC2) were isolated by cell sorting. For T-cell activation assays, FL-DCs were collected, washed with FACS buffer and fixed with $1 \%$ paraformaldehyde for $10 \mathrm{~min}$. Cells were washed with $0.2 \mathrm{M}$ glycine and culture media prior coculture with $\mathrm{CD}^{+} \mathrm{T}$ cells. $1 \times 10^{5}$ fixed DCs were cultured with $1 \times 10^{5} \mathrm{~T}$ cells at $37^{\circ} \mathrm{C}$ for 16 hours to evaluate CD69 or CD25 expression. For proliferation assays, FL-DCs or LN-DCs were collected and immediately cocultured in a 1:1 ratio with CTV-labeled T cells. After 3 days, proliferation was measured by flow cytometry.

\section{In vivo antigen cross-presentation assays}

On day $0,2 \times 10^{6}$ CTV-stained pMEL- $1 \mathrm{CD} 8^{+} \mathrm{T}$ cells were intravenously transferred into C57BL6 mice. On days 1 , 4 and 7 , mice were subcutaneously injected with $20 \mu \mathrm{g}$ of hgp100 peptide plus CCH (200 $\mu$ g), TRIMELVax, B16Vax, $\mathrm{CCH}$ or PBS. On day 10, inguinal, brachial and axillary 
LNs were processed and transferred T-cell proliferation was measured by flow cytometry.

\section{Immunohistochemistry}

Tumors were collected and fixed in $4 \%$ formalin. Threemicrometer-thick sections from paraffin-embedded tissues were mounted on glass slides, rehydrated and antigen retrieval was performed at $100^{\circ} \mathrm{C}$ (TRIS-BorateEDTA (TBE), pH 8). Primary antibodies were used according to manufacturer's instructions (Abcam, dilutions 1:200): anti-CD3 (SP7), anti-CD4 (EPR19514), antiCD8 (ab203035). Slides were incubated with primary antibodies in moist chambers overnight at $4^{\circ} \mathrm{C}$. Slides were washed with PBS before incubation with label-secondary goat antirabbit IgG for 1 hour at $4^{\circ} \mathrm{C}$, washed three times, incubated with DAB substrate KIT (Abcam) solution for $10 \mathrm{~min}$ and washed with PBS. Background staining was performed with Mayer's hematoxylin. Sections were dehydrated through ascending alcohols-to-xylene and mounted.

\section{Humoral response assay}

Indirect ELISA was used to detect antibodies against $\mathrm{CCH}$ in sera of treated mice. ${ }^{28}$ Antibodies against melanoma cells or peripheral blood leucocytes (PBLs) were analyzed by flow cytometry. In brief, $1 \times 10^{5}$ B16F10 or Mel1, Mel2 and Mel3 cell mixtures were incubated with 1:20 dilutions of de-complemented sera. Cells were then incubated with FITC-conjugated anti-mouse IgG (Invitrogen). The binding of serum IgG to target cells was evaluated by flow cytometry.

\section{Preparation of tumor and LN suspensions}

Tumors were dissected, mechanically disaggregated and digested at $37^{\circ} \mathrm{C}$ for $30 \mathrm{~min}$ in Hanks' balanced salt solution (5\% FBS) containing collagenase-D $(1 \mathrm{mg} / \mathrm{mL})$ and DNase I $(25 \mu \mathrm{g} / \mathrm{mL})$ (Roche). The cell suspensions were filtered with $70 \mu \mathrm{m}$ cell strainers (BD Falcon). Leucocytes were suspended in 40\% Percoll (GE Healthcare) and gently layered over $70 \%$ Percoll. The gradient was centrifuged at $750 \mathrm{~g}$ for $20 \mathrm{~min}$ at room temperature. Mononuclear cells were collected, washed and resuspended in complemented RPMI-1640. TdLNs were mechanically disaggregated and cells incubated for $45 \mathrm{~min}$ at $37^{\circ} \mathrm{C}$ in a solution containing $100 \mu \mathrm{g} / \mathrm{mL}$ collagenase-D and $50 \mu \mathrm{g} / \mathrm{mL}$ DNaseI dissolved in 2\% FBS-PBS. Single cell suspensions were washed in RPMI-1640 and depleted of erythrocytes using RBC lysis buffer (BioLegend) for 5 min at $4^{\circ} \mathrm{C}$.

\section{Statistical analysis}

Differences between groups were analyzed by paired, two-tailed Student's t-tests or Mann-Whitney test. Animal survival data were analyzed with the Kaplan-Meier method. Results with a p-value lower than 0.05 were considered significant. Mean values, SEM and statistics were calculated using GraphPad Prism Software.

\section{RESULTS}

HS-conditioned melanoma cell lysates are phagocyted by murine cDCs inducing cross-presentation of MAA in vitro

Here, we investigated the effect of TRIMELVax vaccination using the aggressive murine B16F10 melanoma model (online supplementary figure 1). Taking into account the crucial role of DCs in antitumor responses induced by immunizations, first we asked whether mice BM-DCs were capable to sense TRIMEL-originated DAMPs and to phagocyte, process and present MAAs. Our results showed that BM-derived FLT3-L-differentiated DCs (FLDCs) (online supplementary figure 2) effectively phagocytized both, TRIMEL and B16F10 HS-conditioned cell lysates. In particular, conventional FL-DCs successfully endocyted tumor lysates, while pDC FL-DCs showed lower phagocytic capacity (figure 1A,B). Competitive phagocytosis assays showed that HS-treated B16F10 cell lysates were effectively internalized by cDC1 FL-DCs when incubated in presence of TRIMEL and CCH, suggesting that they may be capable to acquire murine MAA from vaccine components (online supplementary figure 3). Additionally, HS treatment of B16F10 cells also induced ATP and HMGB1 release and calreticulin plasma membrane translocation, similarly to what was observed in HS-treated cell lines composing TRIMEL (online supplementary figure 4). ${ }^{9}$ All the FL-DC subtypes increased CD86 expression when pulsed with TRIMELVax or with each HS-conditioned cell lysate, separately or combined, while CCH failed to induce similar activation (figure 1C).

Optimal delivery of a wide-ranging pool of TAA coupled with factors promoting antigen cross-presentation seems to be critical for cancer vaccine success. TRIMELVaxstimulated FL-DCs induced cross-presentation of the MAA gp100 as indicated by augmented CD69 cell surface expression on pMEL-1 CD ${ }^{+} \mathrm{T}$ cells, in comparison with both $\mathrm{CD}^{+} \mathrm{T}$ cells cultured alone or stimulated with TRIMELVax in absence of DCs, an effect that was more clearly observed when using cDC1 FL-DCs (figure 1D). Furthermore, TRIMELVax-stimulated cDC1 FL-DCs triggered a threefold higher proliferation of $\mathrm{CD}^{+} \mathrm{T}$ cells compared with cDC2 and pDC FL-DCs (figure 1E). Altogether, our data indicate that TRIMELVax elicits efficient DC activation for MAA cross-presentation to $\mathrm{CD}^{+} \mathrm{T}$ cells, particularly mediated by cDC1 FL-DC.

\section{TRIMELVax induces humoral and CDC1-mediated $\mathrm{CD}^{+}{ }^{+} \mathrm{T}$-cell antimelanoma immune responses in vivo}

Then, we assessed whether immune responses elicited by TRIMELVax in vitro translate in protective antitumor effects in vivo. Mice were immunized with TRIMELVax or control treatments (figure 2A). Two days after the last injection, mice were challenged with B16F10 cells and tumor growth was monitored. In this prophylactic setting, the tumor growth was significantly inhibited only in TRIMELVax-treated mice (figure 2B), indicating that the complete vaccine, but not lysates nor adjuvant alone, induces immune responses able to protect mice against tumor challenge. Moreover, no signals of autoimmunity 
A

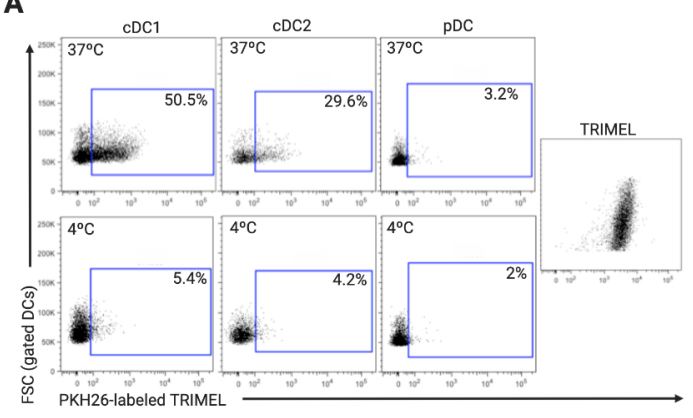

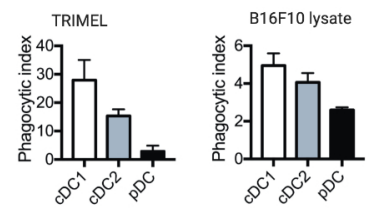

C
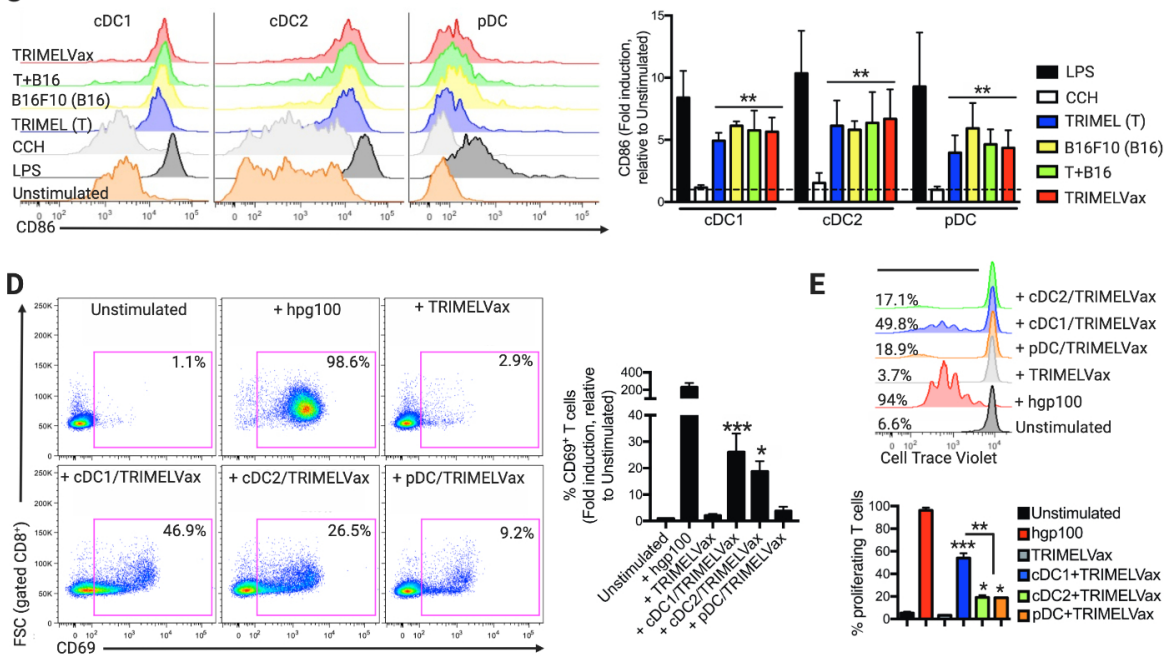

Figure 1 Heatshock (HS)-conditioned melanoma cell lysates are phagocyted by conventional type 1 dendritic cells (cDC1) inducing cross-presentation of melanoma-associated antigen (MAA) in vitro. (A) Bone marrow dendritic cells differentiated with FLT3-L (FL-DCs) were incubated with PKH26-pre-stained TRIMEL (A, B) or B16F10 HS-conditioned cell lysates. Foward scatter (FSC) relative to CD69 expression was analyzed by flow cytometry (B). The percentages of $\mathrm{CDC} 1$, conventional type 2 dendritic cell (cDC2) and plasmacytoid dendritic cell (pDC) FL-DCs acquiring PKH26-labeled TRIMEL are shown in representative dot plots. (B) The bar graphs show the average phagocytic index for three independent experiments using TRIMEL (left) or B16F10 HS-conditioned cell lysate (right). (C) FL-DCs were stimulated with lipopolysaccharide (LPS), Concholepas concholepas hemocyanin (CCH), TRIMEL (T), B16F10 HS-conditioned cell lysate (B16), a 1:1 mixture of TRIMEL:B16F10 HS-conditioned cell lysate (T+B16), TRIMELVax or kept unstimulated. The expression level of CD86 was analyzed by flow cytometry on FL-DCs. The bar graphs (right) show CD86 expression as fold-change relative to unstimulated FL-DCs. (D) pMEL-1 CD8 ${ }^{+} T$ cells were incubated with the peptide gp $100_{25-33}$, TRIMELVax, with sorted and fixed TRIMELVax-loaded FL-DCs or kept unstimulated. CD69 expression was evaluated by flow cytometry. The bar graph (right) shows CD69 expression as fold-change relative to unstimulated T cells. (E) CellTrace Violet (CTV)-preloaded pMEL-1 CD8 ${ }^{+}$T cells were incubated with gp $100_{25-33}$ peptide, TRIMELVax, sorted TRIMELVax-loaded FL-DCs or kept unstimulated. Representative histograms (upper) and graph bars (lower) show the percentage of proliferating $\mathrm{CD}^{+} \mathrm{T}$ cells. Statistical analysis was performed with two-way analysis of variance after Bonferroni correction. ${ }^{*} p<0.05 ;{ }^{* \star} p<0.01 ;{ }^{* \star} p<0.001$.

damage in organs of vaccinated animals were observed (data not shown).

We next investigated whether TRIMELVax-mediated tumor control may be related to eliciting of adaptive antimelanoma immune responses in vivo. To test whether MAA present in TRIMELVax can be efficiently crosspresented to $\mathrm{CD}^{+} \mathrm{T}$ cells in vivo, CTV-preloaded pMEL-1 $\mathrm{CD}^{+} \mathrm{T}$ cells were transferred intravenously into C57BL6 mice. Mice were treated with TRIMELVax, HS-conditioned B16F10 cell lysate+CCH (B16Vax) or PBS. As a positive control, gp100 $25-33$ peptide $+\mathrm{CCH}$ were injected 7 days after T-cell transfer. Three days after treatment, dLNs were sampled and proliferation and activation of pMEL-1 CD8 ${ }^{+} \mathrm{T}$ cells were determined (figure 2C). Our results indicated that TRIMELVax, but not B16Vax, was able to induce potent pMEL-1 $\mathrm{CD}^{+}$T-cell proliferation and activation (figure 2D). These results strongly suggest that TRIMELVax induces cross-presentation of MAA in vivo promoting a cellular-mediated immune response.

cDC1 cells are the main DC subtype responsible for TAA cross-presentation and antitumor $\mathrm{CD} 8^{+}$T-cell activation. ${ }^{29}$ To test whether TRIMELVax was able to provide MAAs to $\mathrm{CDC1}$ in vivo, we performed an ex vivo antigen crosspresentation assay using sorted $\mathrm{cDC1}, \mathrm{cDC} 2$ and $\mathrm{pDCs}$ from TRIMELVax-vaccinated and control B16-FLT3L tumor-bearing animals (figure $2 \mathrm{E}$ and online supplementary figure 5). As predicted, only cDC1 cells isolated from dLNs of TRIMELVax-treated but not those isolated from control mice activated pMEL-1 CD8 ${ }^{+} \mathrm{T}$ cells (figure $2 \mathrm{~F}$ and online supplementary figure 5 ). 

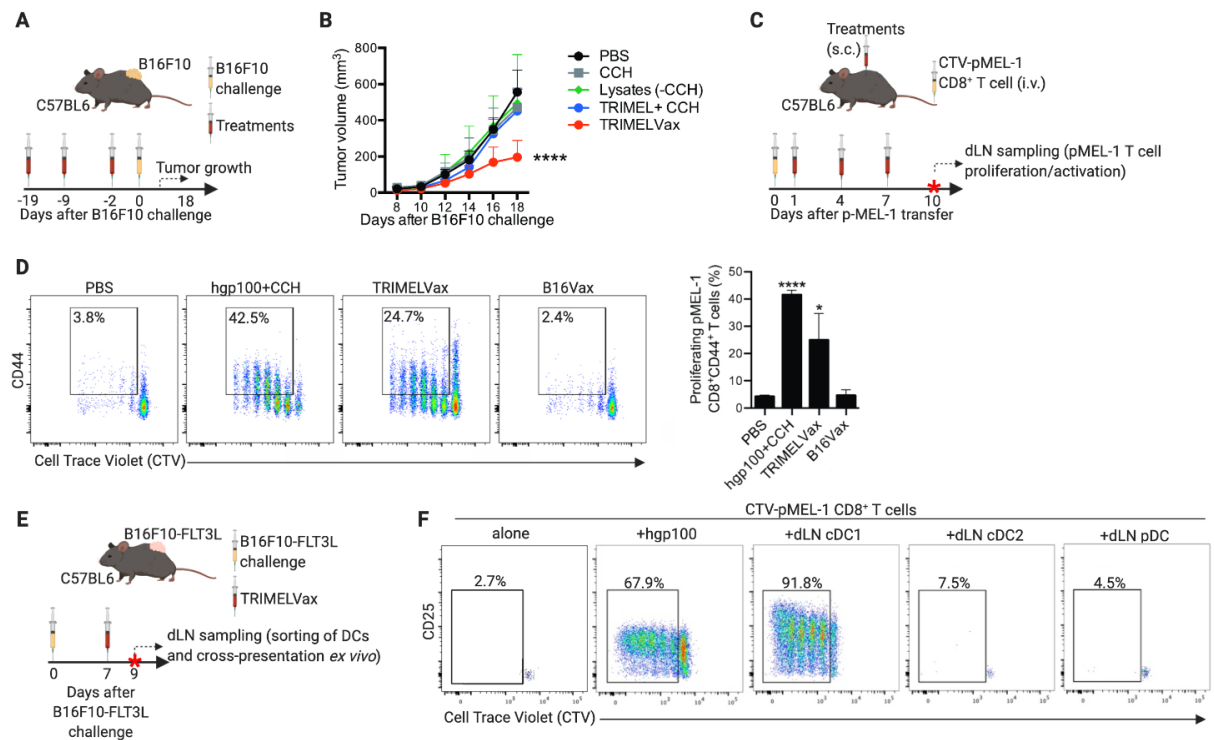

Figure 2 TRIMELVax induces conventional type 1 dendritic cell (CDC1)-mediated CD8 ${ }^{+}$T-cell antimelanoma immune responses in vivo. (A) Schematic representation of prophylactic treatments. (B) Tumor growth curves of mice immunized with different treatments and challenged with B16F10 cells. Each point represents the mean tumor volume \pm SEM per group $(n=7-10)$. (C) Schematic representation of antigen cross-presentation assay. (D) Proliferation (CellTrace Violet (CTV) dilution) and activation (\% of $\left.\mathrm{CD} 44^{+}\right)$of $\mathrm{CD} 8^{+} \mathrm{T}$ cells were determined by flow cytometry. (E) Schematic representation of ex vivo antigen cross-presentation assay. (F) CTV-stained pMEL-1 CD8 ${ }^{+} \mathrm{T}$ cells were cocultured with draining lymph node dendritic cells (dLN-DCs), stimulated with hgp100 peptide or kept unstimulated. The proliferation and activation of the pMEL-1 CD8 ${ }^{+} \mathrm{T}$ cells was determined after 3 days of coculture. The percentage of proliferating T cells are shown in each representative density plot. Statistical analysis was performed with two-way analysis of variance after Bonferroni correction. ${ }^{*} \mathrm{p}<0.05 ;{ }^{* * * *} \mathrm{p}<0.0001$. $\mathrm{CCH}$, Concholepas concholepas hemocyanin; cDC2, conventional type 2 dendritic cell; PBS, phosphate-buffered saline; pDC, plasmacytoid dendritic cell; s.c.,subcutaneously.

TRIMELVax includes $\mathrm{CCH}$, which is a strong adjuvant that induces both T-cell and humoral responses in different vaccine models. ${ }^{26} 30$ Therefore, we investigated the potential presence of antitumor antibodies in sera of vaccinated mice. Our results showed that sera from tumor-bearing mice vaccinated with either TRIMELVax or HS-melanoma cell lysates, but not CCH-treated mice, contains IgGs that bind B16F10 and Mel1/Mel2/Mel3 cells (figure $3 \mathrm{~A}, \mathrm{~B}$ ). Of note, we also observed a strong xeno-response induced by TRIMELVax, given that sera of vaccinated mice also reacts against human PBL (figure 3B). As expected, treatments with $\mathrm{CCH}$ alone or TRIMELVax, but not cell lysates alone, induced the generation of anti-CCH IgGs (figure 3C). These results suggest that TRIMELVax induce a strong humoral immune response against vaccine components, including MAAs.

\section{B16F10 tumor control by TRIMELVax requires HS pretreatment of melanoma cells and presence of $\mathrm{CD4}^{+}$and $\mathrm{CD8}^{+} \mathrm{T}$ cells}

We tested antitumor effects of TRIMELVax in therapeutic vaccination schemes (figure $4 \mathrm{~A}$ ). It was observed that despite DAMP induction in HS-treated B16F10 cells, vaccination with HS-conditioned B16F10 cell lysates was not able to protect against B16F10 tumor growth, even in combination with CCH (B16Vax) (figure 4B). In contrast, TRIMELVax treatment efficiently controlled B16F10 tumor growth (figure 4B). Notably, the effect observed by TRIMELVax was abrogated if untreated B16F10-derived lysate was used as antigen source (4B). As observed in the prophylactic approach, the use of $\mathrm{CCH}$ was required for the antitumor effects mediated by TRIMELVax in the B16F10 melanoma model (figure 4C), but it was dispensable for the control of a more immunogenic tumor as the colon cancer MC38 model (figure 4D). As expected, it was observed that full immune competence was required for TRIMELVax efficacy, given that it did not impact tumor growth in NOD-SCID mice (figure 4E). Moreover, depletion of $\mathrm{CD}^{+}$or, in a major grade, of $\mathrm{CD} 8^{+}$cells abrogated TRIMELVax antitumor effect (figure 4F,G), suggesting that the vaccine may promote both $\mathrm{CD} 8^{+}$and $\mathrm{CD} 4^{+} \mathrm{T}$-cellmediated immunity.

Our results indicated that all components of TRIMELVax were required for an efficient activation of cellular and humoral responses and for controlling tumor growth in a $\mathrm{CD}^{+}$and $\mathrm{CD} 4^{+}$T-cell-dependent manner.

\section{TRIMELVax inhibits tumor growth and increases survival of B16F10 tumor-bearing mice even in the absence of anti-PD-1 therapy}

As anti-PD-1 monotherapy have shown partial protective effects in B16F10 tumors, ${ }^{16}$ we investigated whether the combination of TRIMELVax with anti-PD-1 could improve their immunotherapeutic potentials. Thus, we challenged C57BL6 mice with B16F10 cells and then treated with TRIMELVax, anti-PD-1 monoclonal antibodies or its combination (figure 5A). We observed that both single treatments independently inhibited initial tumor growth with similar efficacy, while the combinatory regimen 
A
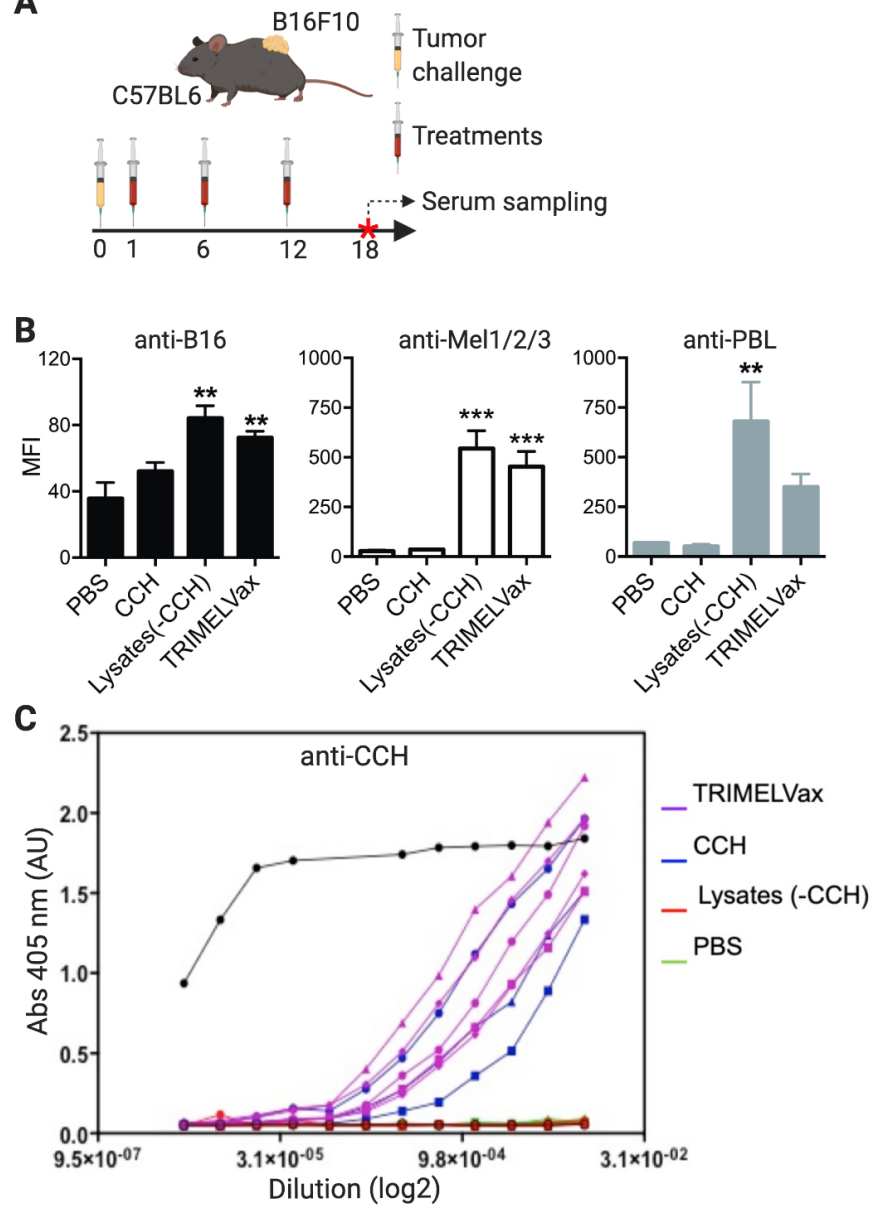

Figure 3 TRIMELVax induces humoral antimelanoma immune responses in vivo. (A) C57BL6 mice (three per group) were challenged subcutaneously with B16F10 cells and then subcutaneously treated as shown. Serum samples were collected 6 days after the last immunization and the presence of IgGs against B16F10, Mel1/Mel2/Mel3 cells, human peripheralblood leucocyte (PBL) (B) or Concholepas concholepas hemocyanin $(\mathrm{CCH})(\mathrm{C})$ were tested by flow cytometry (B) or ELISA (C). (C) The curves represent the anti-CCH antibodies present in different dilution of serum obtained from animals treated with TRIMELVax (purple), $\mathrm{CCH}$ alone (blue), lysates without $\mathrm{CCH}$ (red) or vehicle/phosphatebuffered saline (PBS) (green). The black line corresponds to the detection of purified CCH (ELISA positive control). ${ }^{* *} p<0.01 ;{ }^{* * *} p<0.001$. MFI, Mean of fluorescence. Abs, absorbance.

induced a slightly better inhibition of tumor growth than anti-PD-1 monotherapy (figure 5B,C). However, despite the initial tumor growth control, the survival of anti-PD1-treated animals was similar to the mock-treated ones (figure 5). Remarkably, TRIMELVax treatments alone or in combination with anti-PD-1, induced a significant improvement in the survival of tumor-bearing mice (figure 5D).

\section{TRIMELVax promotes tumor infiltration of CDC1 and PD-1 ${ }^{10}$ CD8 $^{+} T$ cells}

Associated with its better antitumor activity, TRIMELVax induced a higher tumor infiltration of $\mathrm{CD}^{+}, \mathrm{CD}^{+}$ and $\mathrm{CD}^{+}$cells than anti-PD-1 monotherapy, while TRIMELVax/anti-PD-1 combination generated higher tumor infiltration of $\mathrm{CD} 4^{+}$cells than each treatment alone (figure 6A). Flow cytometry analysis of tumors and TdLNs from vaccinated mice, sampled 14 days after tumor challenge, was performed to evaluate whether immune cell compartments were differentially affected by treatments. At that timepoint, both TRIMELVax and anti-PD-1 treatments induced increased frequency of intratumor cDC1s but not cDC2s (figure 6B). Also, we observed a decrease of intratumor macrophages frequency in all treated groups as compared with the PBS-control group (figure 6B). Unlike anti-PD-1 treatment, TRIMELVax induced potent tumor infiltration of $\mathrm{CD}^{+} \mathrm{T}$ cells, being $\mathrm{CD} 8^{+} / \mathrm{CD}^{+} \mathrm{T}$-cell ratio significantly enhanced by TRIMELVax (figure 6B). TRIMELVax/anti-PD-1 combination but not TRIMELVax alone showed a significant increase in the percentage of intratumor B cells (figure 6B). Additionally, we observed significant positive correlations between $\mathrm{CDC1}$ and $\mathrm{CD} 8^{+}$ T-cell intratumor frequency, and between tumor macrophage frequency and tumor size. On the other hand, significant negative correlations between intratumor CD8 ${ }^{+}$T-cell or cDC1 frequency and tumor size were also observed (figure 6C). The TdLN immune cell profile of treated mice is shown in online supplementary figure 6 .

Finally, we wanted to investigate the $\mathrm{CD} 8^{+} \mathrm{T}$-cell lineage phenotypes at tumor microenvironment, comparing their frequencies in tumor-infiltrating lymphocyte (TIL) from animals treated with TRIMELVax versus B16Vax. Although B16Vax therapeutic treatments lead to higher numbers of $\mathrm{CD}^{+}$TILs than TRIMELVax (figure 6D), this non-effective vaccine (figure $4 \mathrm{~B}$ ) lead to the accumulation of a higher proportion of PD- ${ }^{\text {hi }} \mathrm{CD}^{+} \mathrm{T}$ cells, whereas TRIMELVax promoted major proportion of PD-1 ${ }^{\text {lo }} \mathrm{CD}^{+} \mathrm{T}$ cells in tumors, a phenotype associated with prototypic effector cells required for tumor growth control (figure 6E,F).

\section{DISCUSSION/CONCLUSION}

Clinical success of ICB therapies and their attractive combinatorial possibilities have generated enormous interest in cancer immunotherapy. However, limitations in objective responses have motivated a new impetus in the search for alternative/complementary immunological approaches, such as therapeutic cancer vaccines. Cancer vaccines are designed to trigger fresh-specific antitumor cytotoxic $\mathrm{T}$ lymphocyte responses, a prerequisite for clinical effectiveness of ICB. ${ }^{16}$

Despite the efforts, cancer vaccines can still be considered suboptimal. Such inefficient responses maybe related, at least in part, to improper delivery of TAA, induction of tolerance by dominant tumor peptides or immunological danger signal absence during immunization. ${ }^{17-19}$ Although auspicious, technical complexity of DC vaccine preparations has also limited their clinical implementation. However, having in mind the promising results of TRIMEL-loaded TAPCells in patients 
A

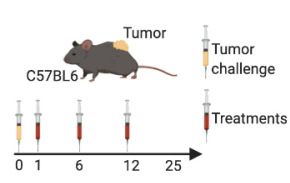

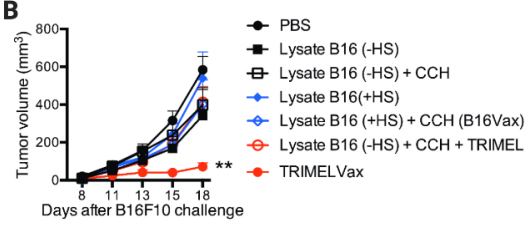

c

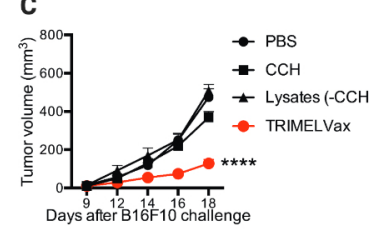

$\mathbf{F}$

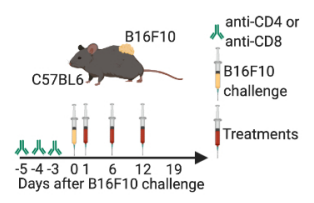

D

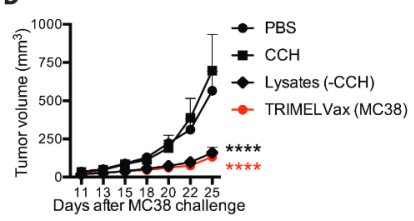

E

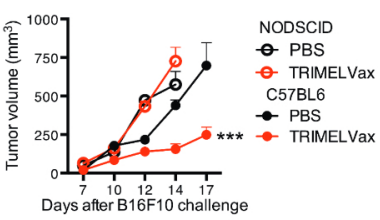

G

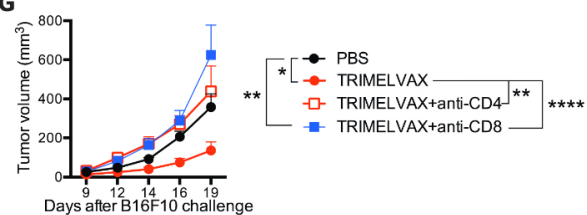

Figure 4 B16F10 tumor control by TRIMELVax requires heatshock (HS) pretreatment of melanoma cells and presence of CD4 ${ }^{+}$ and $C D 8^{+} T$ cells. (A) Schematic representation of the therapeutic protocols used in (B-D). (B, C) Tumor growth curves of treated mice challenge with B16F10. Each point represents the mean tumor volume \pm SEM per group $(n=7$ (B) or=12 (C)). (D) Tumor growth curves of treated mice challenge with MC38. Each point represents the mean tumor volume \pm SEM per group $(n=7)$. (E) Tumor growth curves of C57BL6 or NOD-SCID mice prophylactically treated with TRIMELVax or phosphate-buffered saline (PBS) and challenged with B16F10 cells. Each point represents the mean tumor volume \pm SEM per group $(n=5)$. (F) Schematic representation of therapeutic protocols for $\mathrm{CD} 4^{+}$or $\mathrm{CD} 8^{+}$cell depletions and treatments used in (G). (G) Tumor growth curves of mice depleted or not for $\mathrm{CD} 4^{+}$or $\mathrm{CD}^{+}$cells challenged with B16F10 cells and treated with TRIMELVax. Statistical analysis was performed with two-way analysis of variance after Bonferroni correction. ${ }^{*} p<0.05 ;{ }^{* *} p<0.01 ;{ }^{* \star *} p<0.001 ;{ }^{* \star \star *} p<0.0001 . C C H$, Concholepas concholepas hemocyanin.

with melanoma, ${ }^{89}$ we intended to improve our approach using TRIMEL as a tumor cell lysate vaccine. Intact allogeneic whole-tumor cell and derived lysates have been extensively explored in different immunotherapeutic schedules against cancer. ${ }^{681819}$ Although these vaccines allow for the presentation of multiple TAAs and showed promising results in animal models, they exhibited poor immunogenicity and some have shown very low efficacy in clinical trials. ${ }^{181931}$ The inability of tumor cell lysates to stimulate a sustained immune response may be due in part to the presence of immune suppressive molecules within the lysate or the lack of appropriate neoantigens. ${ }^{31}$ Nevertheless, there is an increasing evidence that, at least under specific circumstances, stressing or damaging tumor cells
A

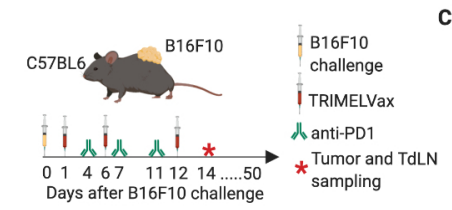

B

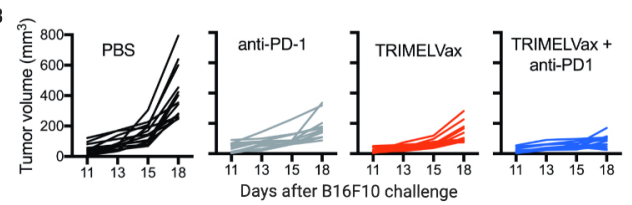

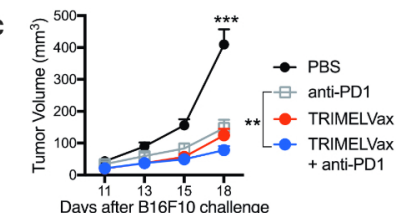

D

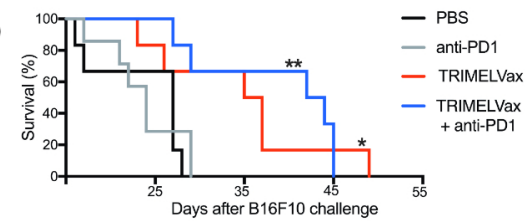

Figure 5 TRIMELVax controls tumor growth and increases survival of B16F10 tumor-bearing mice even in the absence of anti-PD-1 (programmed cell death protein 1) therapy. (A) Schematic representation of the therapeutic protocols for TRIMELVax/ anti-PD-1 combinatory treatments. On day 14 after tumor challenging (asterisk), tumors and tumordraining lymph nodes (TdLNs) were sampled for 4-5 mice per group for further experiments. (B) Tumor growth curves of individual mice. (C) Each point represents the mean tumor volume \pm SEM per group $(n=14)$. Statistical analysis was performed with two-way analysis of variance after Bonferroni correction. ${ }^{* *} p<0.01 ;{ }^{* \star *} p<0.001$. (D) Kaplan-Meier curves for mice survival analysis $(n=6-7$ per group). The median survival time (in days after tumor challenge) per group is: phosphate-buffered saline (PBS), 27; anti-PD-1, 24; TRIMELVax, 36; TRIMELVax+anti-PD-1, 43. Statistical analysis was performed with log-rank (Mantel-Cox) test. " $\mathrm{p}<0.05$; ${ }^{\star \star} p<0.01 ;{ }^{* \star *} p<0.001$. 


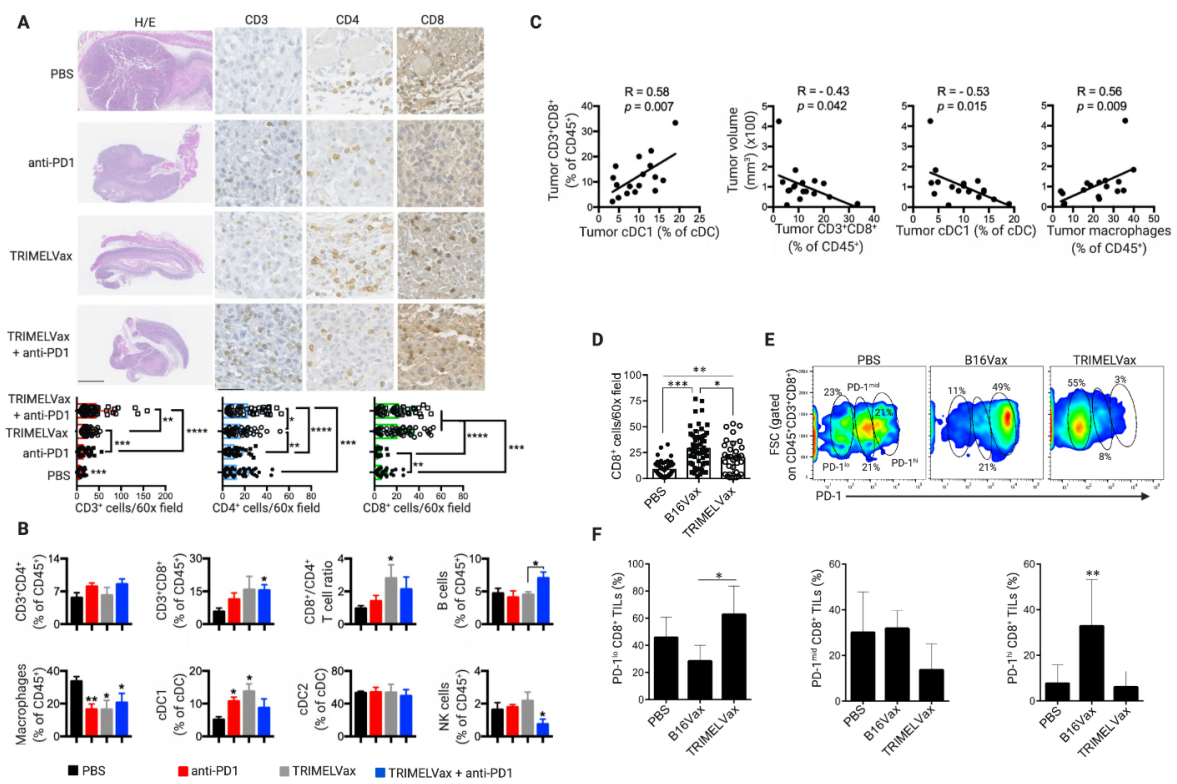

Figure 6 TRIMELVax promotes tumor infiltration of conventional type 1 dendritic cell (cDC1) and programmed cell death protein 1 (PD-1) lo $^{\mathrm{CD}} 8^{+} \mathrm{T}$ cells. (A) Immunohistochemistry analysis for $\mathrm{CD}^{+}, \mathrm{CD} 4^{+}$and $\mathrm{CD} 8^{+}$tumor infiltrating cells of animals treated as described in figure 5. H\&E representative photomicrographs of full tumors (left panels; scale bar: $1 \mathrm{~mm}$ ), and for $\mathrm{CD}^{+}, \mathrm{CD}^{+}$and $\mathrm{CD}^{+}$immune staining of selected tumor areas (scale bar: $40 \mu \mathrm{M}$ ). Dot plot/bar graphs show the quantification of immune cell infiltration by $60 \times$ field of tumors. (B) Tumors were sampled from mice treated as described in figure 5 and immune cell frequencies (among CD45 $5^{+}$cells) were analyzed by flow cytometry. Bar graphs represent average \pm SEM per group $(n=4-5)$. (C) Percentage of intratumor CD8 ${ }^{+}$T cells as a function of the percentage of intratumor cDC1 (left); and tumor volume as a function of the percentage of different immune cells in tumors. Pearson's $r$ correlation values and $p$ values are shown. (D) Dot plot/bar graphs show the quantification of $\mathrm{CD}^{+}$cells by $60 \times$ field of tumors of animals therapeutically treated with TRIMELVax, B16Vax or phosphate-buffered saline (PBS). (E, F) Flow cytometry analysis of PD-1 expression on CD8 ${ }^{+}$tumorinfiltrating lymphocytes (TILs) of animals treated as in (D). The percentage of PD- ${ }^{\text {lo }}, \mathrm{PD}-1^{\text {mid }}$ and PD- $1^{\text {hi }}$ CD8 ${ }^{+}$TILs is showed ( $n=4-6$ animals/group). Statistical analysis was performed with two-way analysis of variance after Bonferroni correction. ${ }^{\star} \mathrm{p}<0.05 ;{ }^{\star \star} \mathrm{p}<0.01 ;{ }^{\star \star \star} \mathrm{p}<0.001 ;{ }^{* \star \star \star} \mathrm{p}<0.0001$.

can drive an inflammatory process that may culminate with the activation of a cell-mediated immune response. ${ }^{32}$ The stress-driven cell activation is now usually referred to as immunogenic cell death. ${ }^{33}$ Diverse treatment modalities, such as photodynamic therapy, high hydrostatic pressure, thermal shock, radiotherapy and some chemotherapeutic agents or oncolytic viruses, have been used to increase tumor cell immunogenicity. However, their proinflammatory effects and ability for induction of DAMPs vary and are dependent of multiple factors like tumor cell types and experimental settings. ${ }^{32-34}$

In this study, we demonstrate that TRIMELVax, a new vaccine based on HS-conditioned tumor cell lysates, inhibits tumor growth and increases B16F10 tumorbearing mice survival. We have previously demonstrated the capacity of the HS-conditioned lysate TRIMEL to induce a mature phenotype in ex vivo generated DCs that are able to trigger antitumor immunity in patients with advanced melanoma and other tumors. ${ }^{8926}$ Treatment of tumor cells with HS prior to cell lysis induces a variety of DAMPs ${ }^{910}$ that represent a requirement for the antitumor effect of TRIMELVax and promote major histocompatibility complex class I antigen presentation through stabilization of antigenic peptides by the chaperones role of HS proteins. ${ }^{35}$
In our experimental settings, although the HS treatment also induces DAMPs in B16F10 cells, and lysates derived from them induced murine DC activation in vitro, these lysates fail to protect mice for B16F10 tumor growth, unless it is combined with TRIMEL and CCH. Previously, we showed that lysates derived from HS-conditioned single cell lines are not always capable of promoting complete DC maturation; this is because not all the required DAMPs are present in every cell line. ${ }^{9} 10$ In contrast, TRIMEL seems to generate the appropriate combination of DAMPs capable of inducing an effective DC maturation. ${ }^{8} \mathrm{CCH}$ has potent immunostimulatory effects, whose adjuvant properties could be partially explained by its carbohydrate-based high complexity and stability, ${ }^{24}$ which activate APCs via the interaction with the C-type lectin and Toll-like receptors (TLRs) such as mannose receptor and TLR4, respectively, ${ }^{25}$ strengthening innate and adaptive immune responses in mammals, making them useful in cancer immunotherapy. 2630

Notably, treatment of B16F10 tumor-bearing mice with TRIMEL/CCH or combined cell lysates in the absence of CCH did not prevent tumor growth (figure 2B), indicating that every vaccine component is crucial for induction of protective responses in our model. At this respect, 
we speculate that $\mathrm{CCH}$ may generate an acute inflammatory milieu at the injection site, promoting innate immune cell recruitment required for potent responses against weakly immunogenic tumors,${ }^{36}$ while TRIMEL may act as an efficient source of immunogenic HS-induced DAMPs that enhance MAA cross-presentation. ${ }^{9}$ Finally, B16F10 HS-cell lysates provide a broad source of syngeneic MAA that may be stabilized by chaperons induced by the HS, as previously described by others. ${ }^{35}$

TRIMELVax capacity for efficiently controlling the weakly immunogenic and aggressive B16F10 melanoma tumor growth, prolonging tumor-bearing mice survival is, to the best of our knowledge, uncommon for vaccines targeting natural TAA based on non-genetically manipulated B16F10 cells or cell lysates. For example, it has been shown that HS-stressed and irradiated B16F10 cells prophylactically injected in mice did not produce tumor growth retardation, unless animals were immunized with LPS-stimulated BM-DCs loaded with stressed B16F10 cells. ${ }^{37}$ Another study showed that mitomycin-inactivated B16F10 cells did not protect mice against tumor growth, requiring genetic modifications to express Glycosylphosphatidylinisotol (GPI)-anchored interleukin 21 and secreting GM-CSF for success. ${ }^{38}$ Additional models of genetically modified B16F10-based vaccines, engineered to express GM-CSF, ${ }^{17}$ FLT3-L ${ }^{14,}{ }^{31}$ or inducible T cell co-stimulator (ICOS) ligand, ${ }^{15}$ produce weak protective antitumor responses, unless they were combined with ICB. $^{39}$

In contrast, monotherapy with TRIMELVax was sufficient to induce potent antitumor responses, even in the absence of anti-PD-1 antibodies. In fact, TRIMELVax/ anti-PD-1 combination generated only marginal enhancing of TRIMELVax efficiency, although long-term effects in tumor-bearing animals cannot be discarded. In our model, treatment of tumor-bearing mice with antiPD-1 alone induced tumor growth retardation, but did not have a significant impact on the overall survival, in line with other observations, ${ }^{40} 41$ which can be explained by acquired resistance to anti-PD-1/PDL1 therapies described in both mouse models and clinical trials. ${ }^{3}{ }^{42} 43$

Furthermore, it has been shown that recruitment of $\mathrm{CD}^{+} \mathrm{T}$ cells into tumors requires the presence of intratumor cDC1 cells. ${ }^{44}$ Accordingly, TRIMELVax immunization resulted in a significant positive correlation between frequencies of intratumor $\mathrm{CDC} 1$ and $\mathrm{CD} 8^{+} \mathrm{T}$ cells. The observed inverse correlation between infiltration of these cell subtypes and tumor size reinforces the importance of inducing "hot tumors" for generating relevant antitumor responses. ${ }^{5}$ Additionally, our in vitro experiments showed that HS-treated cell lysates were preferentially phagocyted by cDC1 cells, which can efficiently cross-present MAA to $\mathrm{CD} 8^{+} \mathrm{T}$ cells in vivo.

On the other hand, we found a significant direct correlation between frequencies of tumor-associated macrophages and tumor size in vaccinated animals. In fact, increased tumor-associated macrophages infiltration in most solid tumors has been correlated with poor patient prognosis ${ }^{45}$ and associated with $\mathrm{CD} 8^{+} \mathrm{T}$-cell tumor microenvironment exclusion and poor response to immunotherapy. ${ }^{46}$

The detection of antimelanoma antibodies in vaccinated mice may indicate that TRIMELVax complex composition appears to facilitate the exposition of surface and intracellular proteins in an acute inflammatory context, which may favor the triggering of humoral responses. Contribution of B cells to tumor immune response is for far less well investigated than T-cell-mediated responses. ${ }^{47}$ Nevertheless, humoral immune responses in patients with cancer have been found against a wide variety of cellular and extracellular proteins derived from transcription factors, cell cycle regulators, cell surface receptors or extracellular matrix. $^{47}$

Chronic antigen stimulation occurring in persistent infections and cancer results in $\mathrm{CD} 8^{+} \mathrm{T}$-cell misfunction. Exhausted $\mathrm{CD}^{+} \mathrm{T}$ cells showed decreased effector function and proliferative capacity, partly caused by the overexpression of inhibitory receptors such as PD-1. Recently, various $\mathrm{CD} 8^{+}$TIL populations have been described based on PD-1 expression levels: negative or low $\left(\mathrm{PD}-1^{\mathrm{N}}\right.$ or PD- $\left.1^{\text {lo }}\right)$; intermediate (PD- $1^{\text {mid }}$ ) and high $\left(\mathrm{PD}-1^{\text {hi }}\right){ }^{48}{ }^{49}$ PD- $1^{\text {hi }} \mathrm{CD}^{+} \mathrm{T}$ cells are characterized by an exhausted phenotype and lower production of proinflammatory cytokines than PD- $1^{\text {lo }}$ CD $8^{+}$T cells. Moreover, PD- $1^{\text {hi }}$ TILs are associated with worse prognosis, whereas high levels of PD- $1^{\text {lo }}$ TIL indicate better clinical outcome for patients with cancer. ${ }^{49}$ Our results showed that TRIMELVax but not controls generated a strong antitumor immune response, reflected by the number of tumor infiltrating $\mathrm{CD}^{+} \mathrm{T}$ cells and also by enhanced prototypic PD- $1^{\mathrm{lo}} \mathrm{CD} 8^{+}$ effector T-cell infiltration preventing dysfunctional PD-1 ${ }^{\text {hi }}$ $\mathrm{CD}^{+}{ }^{\mathrm{T}} \mathrm{T}$-cell accumulation at the tumor site. Although we still do not have an explanation for this observation, it seems that the quality of T-cell priming is reflected in the tumor microenvironment, affecting the effector capacity of the TIL. On the other hand, we cannot rule out that the antigen specificity induced by TRIMELVax is different from that induced by B16Vax, affecting the quality of the resulting CTL.

Evidence shown in this report clearly demonstrates the therapeutic value of TRIMELVax, reflected in the immune-mediated tumor growth inhibition of the aggressive melanoma B16F10. Based on previous observations using TRIMEL-loaded DC vaccines, TRIMELVax translation to clinical trials will be favored by demonstrated TRIMEL properties as optimal supplier of a variety of shared MAAs, and source of necessary DAMPs to induce an appropriate in vivo antigen cross-presentation. Finally, the experimental model used in the present study provides an excellent system to further investigate cellular and molecular factors that may be essential to trigger protective tumor immune responses by active immunotherapy.

\section{Author affiliations}

${ }^{1}$ Disciplinary Program of Immunology, Institute of Biomedical Sciences, Faculty of Medicine, Universidad de Chile, Santiago, Chile 
${ }^{2}$ Millennium Institute on Immunology and Immunotherapy, Faculty of Medicine, Universidad de Chile, Santiago, Chile

${ }^{3}$ Programa Institucional de Fomento a la Investigación, Desarrollo e Innovación, Universidad Tecnológica Metropolitana, Santiago, Chile

${ }^{4}$ Fundación Ciencia y Tecnología para el Desarrollo (FUCITED), Avenida Eduardo Castillo Velasco 2902, Santiago, Chile

${ }^{5}$ Biosonda Corporation, Avenida Eduardo Castillo Velasco 2902, Santiago, Chile ${ }^{6}$ Laboratory of Experimental Immunology \& Cancer, Faculty of Dentistry, Universidad de Chile, Santiago, Chile

Acknowledgements We thank Dr Álvaro Lladser (Fundación Ciencia \& Vida, Chile) for providing antibodies for cell depletion and for critical discussions, Dr María Rosa Bono (Universidad de Chile) for providing the B16F10 cells expressing FLT3L, Dr Fabiola Osorio (Universidad de Chile) for providing FLT3L, Michelle Salazar (FUCITED) and Dr Benedict Chambers (Karolinska Institute, Sweden) for critical reading of manuscript, and Marisol Briones for administrative and technical support.

Contributors Conceptualization and research designing (MAG, CP, AT, FEG, MNL, FS-0), conducting experiments (MAG, CP, MN, CF, IA, FT, JPA), acquiring data (MAG, $\mathrm{MN}$, CF, IA, FT, JPA), analyzing data (MAG, AT, MN, CF, IA, FT, JPA, MNL, FS-0), providing reagents (MIB, MNL, FS-0), writing the manuscript (MAG, AT, MIB, MN, FEG, MNL, FS-0), and supervision and final manuscript revision (FS-0).

Funding This work was founded by grants from the National Fund for Scientific and Technological Development (FONDECYT 1171213, 11160380 and 3170917); Fund for the Promotion of Scientific and Technological Development (FONDEF ID16l10148) and the Millennium Science Initiative from the Ministry for the Economy, Development and Tourism (P09/016-F).

Competing interests None declared.

Patient consent for publication Not required.

Ethics approval All animal experiments were performed in accordance with institutional guidelines for animal care and were approved by the Ethical Review Committee at the Universidad de Chile, ethical number CBA0885 (approval date: May 2016).

Provenance and peer review Not commissioned; externally peer reviewed.

Data availability statement All the data and material published are available under reasonable request.

Open access This is an open access article distributed in accordance with the Creative Commons Attribution 4.0 Unported (CC BY 4.0) license, which permits others to copy, redistribute, remix, transform and build upon this work for any purpose, provided the original work is properly cited, a link to the licence is given, and indication of whether changes were made. See https://creativecommons.org/ licenses/by/4.0/.

\section{ORCID iD}

Andrés Tittarelli http://orcid.org/0000-0003-4129-9734

\section{REFERENCES}

1 Hodi FS, O'Day SJ, McDermott DF, et al. Improved survival with ipilimumab in patients with metastatic melanoma. $N$ Engl J Med 2010;363:711-23.

2 Sharma P, Allison JP. Immune checkpoint targeting in cancer therapy: toward combination strategies with curative potential. Cell 2015;161:205-14.

3 Khair DO, Bax HJ, Mele S, et al. Combining immune checkpoint inhibitors: established and emerging targets and strategies to improve outcomes in melanoma. Front Immunol 2019;10:453.

4 Ribas A, Dummer R, Puzanov I, et al. Oncolytic virotherapy promotes intratumoral T cell infiltration and improves anti-PD-1 immunotherapy. Cell 2017;170:1109-19.

5 Bonaventura P, Shekarian T, Alcazer V, et al. Cold tumors: a therapeutic challenge for immunotherapy. Front Immunol 2019;10:168.

6 Melief CJM, van Hall T, Arens R, et al. Therapeutic cancer vaccines. J Clin Invest 2015;125:3401-12.

7 Kantoff PW, Higano CS, Shore ND, et al. Sipuleucel-T immunotherapy for castration-resistant prostate cancer. N Engl J Med 2010;363:411-22.

8 López MN, Pereda C, Segal G, et al. Prolonged survival of dendritic cell-vaccinated melanoma patients correlates with tumor-specific delayed type IV hypersensitivity response and reduction of tumor growth factor beta-expressing T cells. J Clin Oncol 2009;27:945-52.

9 Aguilera R, Saffie C, Tittarelli A, et al. Heat-shock induction of tumorderived danger signals mediates rapid monocyte differentiation into clinically effective dendritic cells. Clin Cancer Res 2011;17:2474-83.

10 Rojas-Sepúlveda D, Tittarelli A, Gleisner MA, et al. Tumor lysatebased vaccines: on the road to immunotherapy for gallbladder cancer. Cancer Immunol Immunother 2018;67:1897-910.

11 Tittarelli A, González FE, Pereda C, et al. Toll-like receptor 4 gene polymorphism influences dendritic cell in vitro function and clinical outcomes in vaccinated melanoma patients. Cancer Immunol Immunother 2012;61:2067-77.

12 Durán-Aniotz C, Segal G, Salazar L, et al. The immunological response and post-treatment survival of DC-vaccinated melanoma patients are associated with increased Th1/Th17 and reduced Th3 cytokine responses. Cancer Immunol Immunother 2013;62:761-72.

13 Ledford $\mathrm{H}$. Therapeutic cancer vaccine survives biotech bust. Nature 2015;519:17-18.

14 Baghdadi M, Nagao H, Yoshiyama H, et al. Combined blockade of TIM-3 and TIM-4 augments cancer vaccine efficacy against established melanomas. Cancer Immunol Immunother 2013;62:629-37.

15 Fan X, Quezada SA, Sepulveda MA, et al. Engagement of the ICOS pathway markedly enhances efficacy of CTLA-4 blockade in cancer immunotherapy. J Exp Med 2014;211:715-25.

16 Curran MA, Montalvo W, Yagita H, et al. PD-1 and CTLA-4 combination blockade expands infiltrating $T$ cells and reduces regulatory $\mathrm{T}$ and myeloid cells within $\mathrm{B} 16$ melanoma tumors. Proc Natl Acad Sci U S A 2010;107:4275-80.

17 Dranoff G, Jaffee E, Lazenby A, et al. Vaccination with irradiated tumor cells engineered to secrete murine granulocyte-macrophage colony-stimulating factor stimulates potent, specific, and long-lasting anti-tumor immunity. Proc Natl Acad Sci U S A 1993;90:3539-43.

18 Kusumoto M, Umeda S, Ikubo A, et al. Phase 1 clinical trial of irradiated autologous melanoma cells adenovirally transduced with human GM-CSF gene. Cancer Immunol Immunother 2001;50:373-81.

19 Soiffer R, Hodi FS, Haluska F, et al. Vaccination with irradiated, autologous melanoma cells engineered to secrete granulocytemacrophage colony-stimulating factor by adenoviral-mediated gene transfer augments antitumor immunity in patients with metastatic melanoma. J Clin Oncol 2003;21:3343-50.

20 Vandenberk L, Belmans J, Van Woensel M, et al. Exploiting the immunogenic potential of cancer cells for improved dendritic cell vaccines. Front Immunol 2015;6:663.

21 Huang M-N, Nicholson LT, Batich KA, et al. Antigen-loaded monocyte administration induces potent therapeutic antitumor $\mathrm{T}$ cell responses. J Clin Invest 2020;130:128267:774-88.

22 Yewdall AW, Drutman SB, Jinwala F, et al. CD8+ T cell priming by dendritic cell vaccines requires antigen transfer to endogenous antigen presenting cells. PLoS One 2010;5:e11144.

23 Wimmers F, de Haas N, Scholzen A, et al. Monitoring of dynamic changes in keyhole limpet hemocyanin (KLH)-specific B cells in $\mathrm{KLH}$ vaccinated cancer patients. Sci Rep 2017;7:43486.

24 Salazar ML, Jiménez JM, Villar J, et al. N-Glycosylation of mollusk hemocyanins contributes to their structural stability and immunomodulatory properties in mammals. J Biol Chem 2019;294:19546-64.

25 Jiménez JM, Salazar ML, Arancibia S, et al. TIr4, but neither Dectin-1 nor dectin-2, participates in the mollusk Hemocyanin-Induced proinflammatory effects in antigen-presenting cells from mammals. Front Immunol 2019;10:1136.

26 Reyes D, Salazar L, Espinoza E, et al. Tumour cell lysate-loaded dendritic cell vaccine induces biochemical and memory immune response in castration-resistant prostate cancer patients. $\mathrm{Br} \mathrm{J}$ Cancer 2013;109:1488-97.

27 Moltedo B, Faunes F, Haussmann D, et al. Immunotherapeutic effect of concholepas hemocyanin in the murine bladder cancer model: evidence for conserved antitumor properties among hemocyanins. $J$ Urol 2006;176:2690-5.

28 Oliva H, Moltedo B, De loannes $\mathrm{P}$, et al. Monoclonal antibodies to molluskan hemocyanin from Concholepas concholepas demonstrate common and specific epitopes among subunits. Hybrid Hybridomics 2002;21:365-74.

29 Noubade R, Majri-Morrison S, Tarbell KV. Beyond cDC1: emerging roles of DC crosstalk in cancer immunity. Front Immunol 2019;10:1014.

30 Cho H-I, Reyes-Vargas E, Delgado JC, et al. A potent vaccination strategy that circumvents lymphodepletion for effective antitumor adoptive T-cell therapy. Cancer Res 2012;72:1986-95. 
31 Srivatsan S, Patel JM, Bozeman EN, et al. Allogeneic tumor cell vaccines: the promise and limitations in clinical trials. Hum Vaccin Immunother 2014;10:52-63.

32 Kroemer G, Galluzzi L, Kepp O, et al. Immunogenic cell death in cancer therapy. Annu Rev Immunol 2013;31:51-72.

$33 \mathrm{LiX}$. The inducers of immunogenic cell death for tumor immunotherapy. Tumori 2018;104:1-8.

34 Galluzzi L, Vitale I, Warren S, et al. Consensus guidelines for the definition, detection and interpretation of immunogenic cell death. $J$ Immunother Cancer 2020;8:e000337.

35 Srivastava P. Interaction of heat shock proteins with peptides and antigen presenting cells: chaperoning of the innate and adaptive immune responses. Annu Rev Immunol 2002;20:395-425.

36 Zhong T-Y, Arancibia S, Born R, et al. Hemocyanins stimulate innate immunity by inducing different temporal patterns of proinflammatory cytokine expression in macrophages. $\mathrm{J}$ Immunol 2016;196:4650-62.

37 Prasad SJ, Farrand KJ, Matthews SA, et al. Dendritic cells loaded with stressed tumor cells elicit long-lasting protective tumor immunity in mice depleted of CD4+CD25+ regulatory T cells. $J$ Immunol 2005;174:90-8.

38 Zhao F, Dou J, He XF, et al. Enhancing therapy of B16F10 melanoma efficacy through tumor vaccine expressing GPI-anchored IL-21 and secreting GM-CSF in mouse model. Vaccine 2010;28:2846-52.

39 Simpson TR, Li F, Montalvo-Ortiz W, et al. Fc-dependent depletion of tumor-infiltrating regulatory $T$ cells co-defines the efficacy of antiCTLA-4 therapy against melanoma. J Exp Med 2013;210:1695-710.

40 They L, Michaud H-A, Becquart O, et al. PD-1 blockade at the time of tumor escape potentiates the immune-mediated antitumor effects of a melanoma-targeting monoclonal antibody. Oncoimmunology 2017;6:e1353857.

41 Cervera-Carrascon V, Siurala M, Santos JM, et al. TNFa and IL-2 armed adenoviruses enable complete responses by anti-PD-1 checkpoint blockade. Oncoimmunology 2018;7:e1412902.

42 Restifo NP, Smyth MJ, Snyder A. Acquired resistance to immunotherapy and future challenges. Nat Rev Cancer 2016;16:121-6.

43 Braun DA, Burke KP, Van Allen EM. Genomic approaches to understanding response and resistance to immunotherapy. Clin Cancer Res 2016;22:5642-50.

44 Spranger S, Dai D, Horton B, et al. Tumor-Residing Batf3 dendritic cells are required for effector $\mathrm{T}$ cell trafficking and adoptive $\mathrm{T}$ cell therapy. Cancer Cell 2017;31:711-23.

45 Poh AR, Ernst M. Targeting macrophages in cancer: from bench to bedside. Front Oncol 2018;8:49.

46 Peranzoni E, Lemoine J, Vimeux L, et al. Macrophages impede CD8 $T$ cells from reaching tumor cells and limit the efficacy of anti-PD-1 treatment. Proc Natl Acad Sci U S A 2018;115:E4041-50.

47 Reuschenbach M, von Knebel Doeberitz M, Wentzensen N. A systematic review of humoral immune responses against tumor antigens. Cancer Immunol Immunother 2009;58:1535-44.

48 Thommen DS, Koelzer VH, Herzig P, et al. A transcriptionally and functionally distinct PD $-1^{+} \mathrm{CD} 8^{+} \mathrm{T}$ cell pool with predictive potential in non-small-cell lung cancer treated with PD-1 blockade. Nat Med 2018;24:994-1004.

49 Kansy BA, Concha-Benavente F, Srivastava RM, et al. PD-1 Status in $\mathrm{CD}^{+} \mathrm{T}$ Cells Associates with Survival and Anti-PD-1 Therapeutic Outcomes in Head and Neck Cancer. Cancer Res 2017;77:6353-64. 